\title{
Social Protection for Older Women
}

\author{
By Isabel Ortiz and Florian Juergens
}

$G^{-}$

ender equality and women's empowerment are increasingly prominent themes on the international policy agenda. The empowerment of women is essential for realising the Sustainable Development Goals (SDGs) by 2030 , agreed by all countries at the United Nations in 2015.

Also at the forefront of the development agenda is social protection, or social security, and its SDG target 1.3, committing countries to implement national social protection systems for all, including floors, to prevent and reduce poverty and inequality.

Without considering older women, the SDGs and other UN commitments risk failure. The number of people aged 60 or over was 962 million in 2017, more than twice as large as in 1980 - of which 54 percent are women. Understanding demographic trends is crucial for implementing the UN 2030 Agenda, and countries must leverage the opportunities to address the needs and rights of older women as well as men, including those related to labour markets, health and care systems, and social protection.

\section{Extending Pension Coverage to All Older Women and Men}

Pensions are the most widespread form of social protection. At the global level 68 percent of older people receive a pension, and there is significant progress in recent years. However, there are large regional variations. The Americas,
Europe and Central Asia have largely universal coverage, while in Sub-Saharan Africa, Southern Asia and the Arab States less than 30 percent of older persons receive a pension (see figure).

Women are less likely than men to receive a pension, and if they do, they have considerably lower benefit levels. Even in countries where women enjoy widespread pension coverage, their benefit levels are often considerably lower than men's. For example, according to a recent EU Commission report, men on average are entitled to pensions which are greater than those of women by 40 percent, though some European countries manage to reduce the pension gap to below 7 percent, such as in Estonia, Denmark and Norway, as presented below.

\section{Women's Life-course and Pension Coverage}

Throughout their lives, women and men are exposed to different vulnerabilities and disadvantages, which are often specific to their gender. For women, inequalities in older age stem from the accumulation of multiple and interconnected discrimination and inequalities, such as education and wage differentials, gendered work norms, productive and reproductive roles, and lack of voice and agency.

Women are more likely than men to live in poverty at all ages, but in older age the difference is more significant. They are less able to rely on savings in older age as they have often worked fewer years and earned less in that time. In many countries, women's jobs tend to be in informal and low-paid employment. Finding well-paid jobs may be difficult due to lesser access to formal education and training, while unpaid family care responsibilities absorb much of their time.

While the better-off may be able to ensure income security in their old-age through savings, assets or the support of their family, the reality faced by most of the world's population is that sources of income are low and unreliable, even during their most productive years. This makes it almost impossible for anyone but the wealthiest to rely on private savings as a main source of support in the final years.

This is particularly true for older women. After a lifetime of disadvantage, discrimination and unpaid work, they arrive at older age with limited economic and social assets to call upon. There is an urgent need for universal and gender-equitable social protection and pension systems to redress this.

\section{Making Social Policies Work for Women}

Public policies need to address the root causes of gender inequalities, particularly in education, employment and social protection, including care. To start, greater efforts are necessary to support women's economic empowerment through eliminating discrimination in the labour market and wider society 


\section{Pensions: Effective Coverage for Older Persons by World Region}

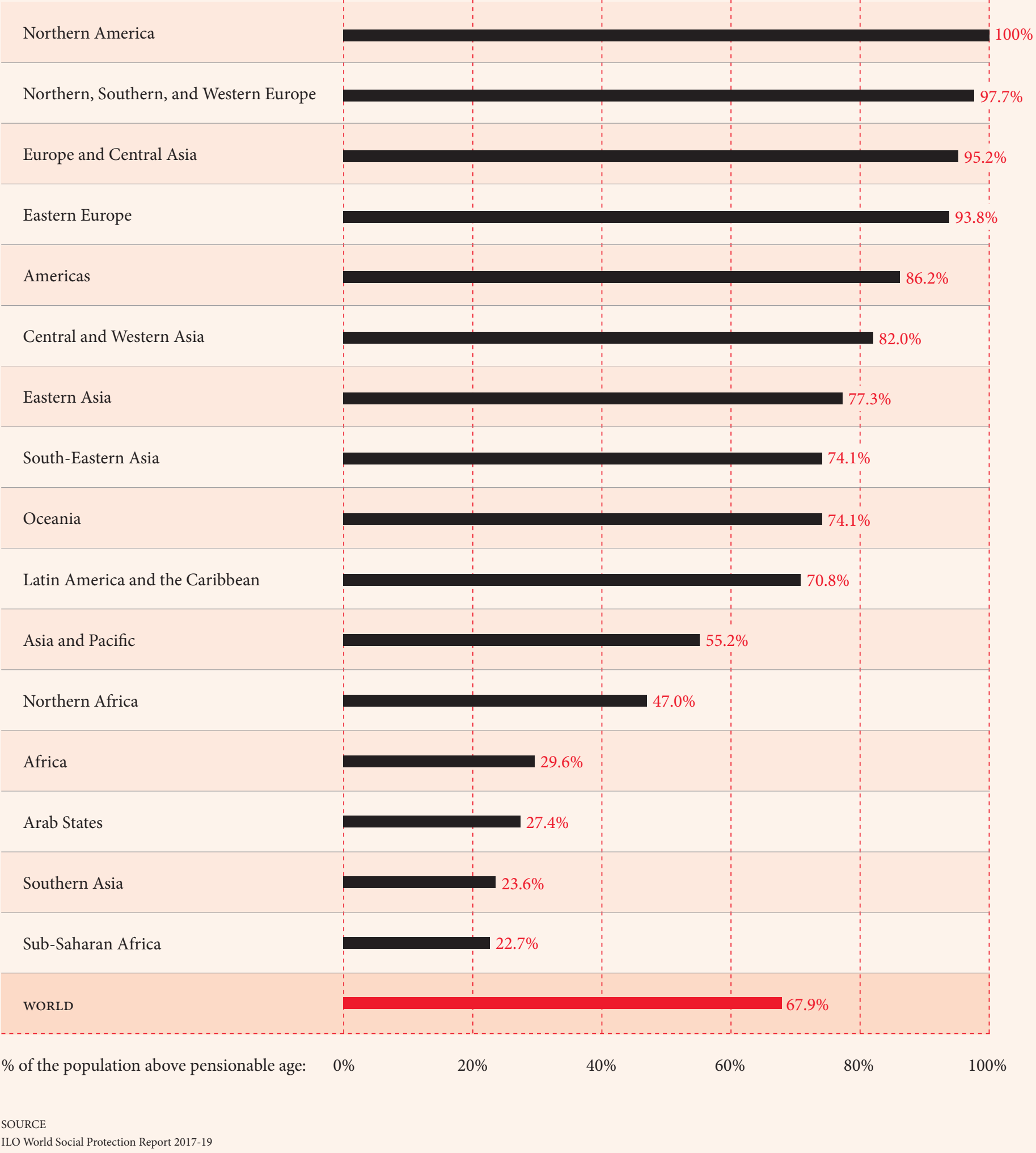




\section{"While women's disadvantage in older age is mainly a result of discrimination throughout the life-course, the design of gender-sensitive pension systems is essential."}

and increasing women's access to decent work.

Unpaid care work is the main barrier preventing women from getting into, remaining and progressing in the labour force. Recent ILO figures show that globally women are performing more than three-quarters of the time spent in unpaid care work, more than three times as much as men. Sweeping changes in social policies should address the rising need for care and tackle the huge disparity between women's and men's unpaid care responsibilities. While women's disadvantage in older age is mainly a result of discrimination throughout the life-course, the design of gender-sensitive pension systems is essential. This is relevant for both social insurance and social assistance.

\section{Social Pensions are Key to Reduce Poverty for Older Women}

With regards to the social assistance, the good news is that more and more countries are implementing non-contributory social pensions, often on a universal basis, which provide a basic stipend for all older women and men.

Non-contributory social pensions are becoming an increasingly important element of public pension policy, particularly in the attempts of lower and middle-income countries to achieve universal coverage through a mix of social insurance, financed by contributions, and social assistance, financed from the general budget.
Universal pension systems combining social pensions and contributory pensions have been developed in Argentina, Belarus, Bolivia, Botswana, Cabo Verde, China, Georgia, Kenya, Kyrgyzstan, Lesotho, Maldives, Mauritius, Mongolia, Namibia, Seychelles, South Africa, Swaziland, Timor-Leste, Trinidad and Tobago, Ukraine, Uruguay, Uzbekistan and Zanzibar (Tanzania). Other countries made considerable progress in recent years and have near universal pension coverage.

Social pensions are not based on continuous participation in paid formal sector employment and therefore more accurately reflect women's life-courses. To ensure that social pensions effectively reach all older women, especially the marginalized, social pensions should be provided on a universal basis.

Evidence shows they bolster women's economic autonomy, strengthen their voice and agency, and can be an effective way of recognising the value of women's unpaid work.

However, benefit levels are often insufficient to meet the needs of older women and should be increased and appropriately indexed to ensure basic income security.

\section{Improving Social Insurance} Pensions - Learning from Norway Most people aim to receive better benefits than those currently provided by basic social assistance schemes, 
including social pensions, which is why social insurance is so important and why it is key that women's standing in such schemes is improved.

Fortunately, public social insurance increasingly contains elements to counteract gender inequalities, such as by recognizing maternity and time spent on unpaid care as contributory years, or by introducing a minimum guaranteed pension level. For instance, the redistributive mechanism in the Norwegian pension and tax system reduces the 43 percent income difference between working women and men to only seven per cent in pension income.

This type of gender-sensitive redistributive mechanism is not found in privatized pensions systems. In the 30 countries that privatized pensions over the last three decades, women's inequality has been exacerbated. The redistributive components of public social security systems were eliminated with the introduction of individual accounts that more narrowly reflect a person's lifetime earnings. As a result, those with low incomes or unable to work, even if temporarily, had very small savings and consequently ended up with small pensions.

Public social insurance schemes, based on solidarity and collective financing, are by far the most widespread form of old-age protection globally, and, if we follow the lead from Norway, have the potential to significantly reduce gendered inequalities in older age.
Recognizing this, many countries are exploring strategies to expand the coverage of contributory schemes in the informal economy, where women are overrepresented. The Uruguayan Monotax, a simplified scheme for micro and small enterprises to pay taxes and make social security contributions, is a good example of such innovation and 60 percent of its affiliates are women.

To conclude, this article has briefly presented key social protection issues for older women, agreed by all countries in the Sustainable Development Goals and other UN commitments. Such social protection policies can only be part of the solution and lasting transformative change will require concerted efforts to address the root causes of gender inequalities throughout the lifecourse, including public policies to address unpaid care work, women's empowerment, access to decent work and to equitable social security systems, to effectively address the needs and rights of older women.

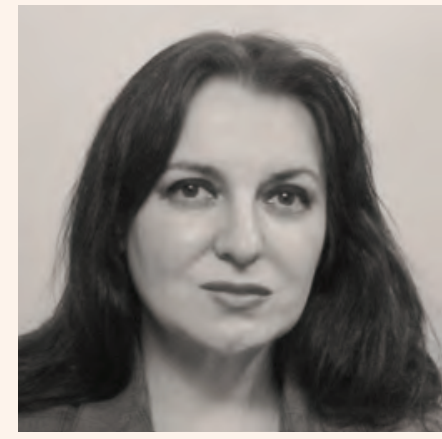

Isabel Ortiz DIRECTOR OF SOCIAL PROTECTION, UNITED NATIONS INTERNATIONAL LABOUR ORGANIZATION (ILO)

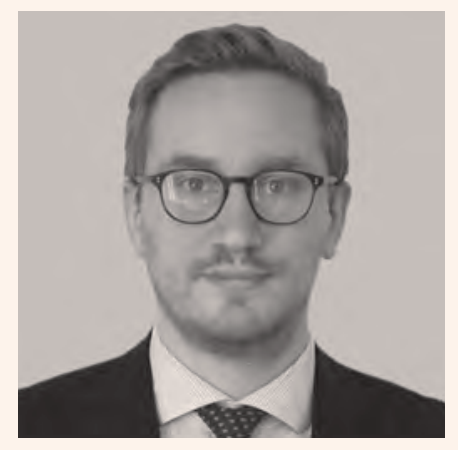

Florian Juergens GLOBAL SOCIAL PROTECTION ADVISOR, HELPAGE INTERNATIONAL 